\title{
The effect of tranexamic acid on artificial joint materials: a biomechanical study (the bioTRANX study)
}

\author{
Sattar Alshryda $\cdot$ James M. Mason • \\ Praveen Sarda $\cdot$ T. Lou $\cdot$ Martin Stanley • \\ Junjie Wu $\cdot$ Anthony Unsworth
}

Received: 23 March 2014/ Accepted: 28 June 2014/Published online: 5 August 2014

(C) The Author(s) 2014. This article is published with open access at Springerlink.com

\begin{abstract}
Background Tranexamic acid (TXA) has been successfully used to reduce bleeding in joint replacement. Recently local TXA has been advocated to reduce blood loss in total knee or hip replacement; however, this raised concerns about potential adverse effects of TXA upon the artificial joint replacement.

Materials and methods In this biomechanical study we compared the effects of TXA and saline upon the following
\end{abstract}

S. Alshryda $(\bowtie) \cdot$ T. Lou

Departments of Trauma and Orthopaedics, Central Manchester

University Hospitals, Oxford Road,

Manchester M13 9WL, Lancashire, UK

e-mail: Sattar26@doctors.org.uk

T. Lou

e-mail: nurn1981@yahoo.co.uk

J. M. Mason

School of Medicine and Health, Wolfson Research Centre,

Queen Campus, Durham University,

Stockton on Tees TS17 6BH, UK

e-mail: j.m.mason@durham.ac.uk

P. Sarda

Departments of Trauma and Orthopaedics, Medway Maritime Hospital, Windmill Road, Gillingham, Kent ME7 5NY, UK

e-mail: praveensarda2003@yahoo.com

M. Stanley $\cdot$ J. Wu $\cdot$ A. Unsworth

Centre for Biomedical Engineering School of Engineering and Computing Sciences, Durham University, Durham DH1 3LE, UK

e-mail: m.j.stanley@leeds.ac.uk

J. Wu

e-mail: junjie.wu@durham.ac.uk

A. Unsworth

e-mail: tony.unsworth@durham.ac.uk biomechanical properties of artificial joint materials-(1) tensile properties (ultimate strength, stiffness and Young's modulus), (2) the wear rate using a multi-directional pinon-plate machine, and (3) the surface topography of pins and plates before and after wear rate testing.

Results There were no significant differences in tensile strength, wear rates or surface topography of either ultrahigh-molecular-weight polyethylene pins or cobalt chromium molybdenum metal plates between specimens soaked in TXA and specimens soaked in saline.

Conclusion Biomechanical testing shows that there are no biomechanical adverse affects on the properties of common artificial joint materials from using topical TXA. Level of evidence $\mathrm{V}$

Keywords Topical · Local - Tranexamic acid · Arthroplasty · Joint replacement · Blood loss · Blood transfusion - Wear rate - Surface topography . Biomechanical profile

\section{Introduction}

A major cause of artificial joint failure is the loosening that occurs as a consequence of wear and tear of the bearing surfaces. Even a well performing prosthetic joint releases billions of microscopic wear particles (debris) into the joint space. When an excessive amount of debris is generated it may stimulate a severe body reaction in the capsular tissues and bone leading to inflammation and osteolysis. The resulting loss of supporting bone may lead to loosening of the implants requiring difficult revision surgery.

Most artificial joints consist of two metal surfaces, commonly made of cobalt chromium molybdenum (Co$\mathrm{Cr}-\mathrm{Mo}$ ) alloy and an insert, commonly made of ultra-high- 
molecular-weight polyethylene (UHMWPE). The mechanical properties of these two materials are influenced by several chemical and physical factors. Oxidation breaks down the molecular chains in UHMWPE resulting in increased brittleness and reduced resistance to crack propagation. Historically, there have been unfortunate consequences within artificial joints when unexpected and unwanted chemical or physical reactions led to severe wear and joint failure. One example arose from the storage of artificial implants in air-filled packets after sterilisation using gamma radiation. This mode of storage led to gradual oxidation of the UHMWPE and deterioration of its mechanical properties. This was partly overcome by storage within a vacuum-sealed packet. Another example was post-irradiation thermal treatment to reduce free radicals in the polyethylene. This could cause a partial reduction in crystallinity of the material that, in turn, reduced the resistance to crack propagation [1].

Intravenous tranexamic acid (TXA) has been shown to reduce blood loss and transfusion in joint replacement [216]; however, fear of systemic side-effects precludes its wide use in orthopaedic practice. Locally administered TXA has been advocated as a better alternative due its easier preparation and administration, higher concentration at the bleeding site and less systemic side-effects [17-21]. There is a legitimate concern that TXA might adversely affect the biomechanical properties of artificial implants, especially the wear rate which might lead to subsequent loosening and failure. A rigorous search of the published literature, contact with manufacturers and contact with the community publishing on the use of TXA uncovered no research to address this issue. Consequently, this is the first study to investigate the effect of local TXA upon artificial joint biomechanical properties and performance. The research is named the bioTRANX study.

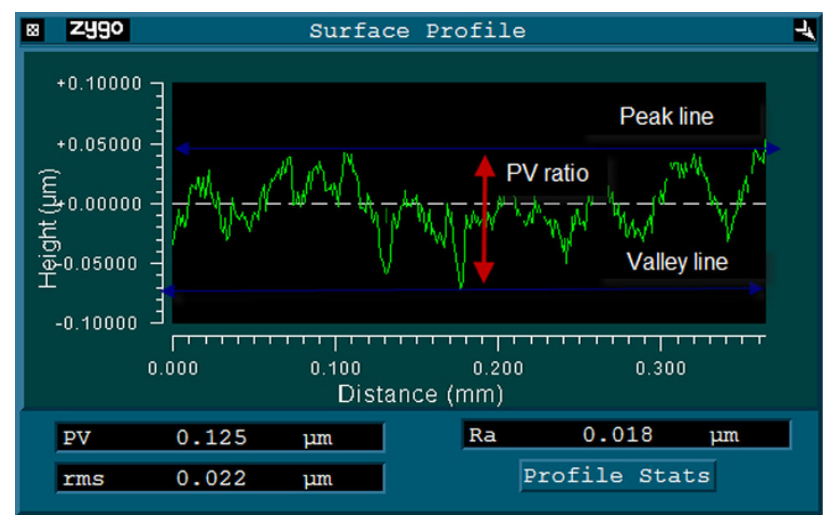

Fig. 1 Peak-valley ratio (PV): the distance between the highest peak and the deepest valley over the entire evaluation length

\section{Materials and methods}

In this biomechanical study we investigated the effects of TXA on the following biomechanical properties of artificial joint materials as surrogates for long-term effects:

1. Tensile properties of the UHMWPE (ultimate strength, stiffness and Young's modulus).

2. The wear rate using a multi-directional pin-on-plate machine. Pins were made of UHMWPE and plates were made of $\mathrm{Co}-\mathrm{Cr}-\mathrm{Mo}$.

3. The surface topography of pins and plates before and after wear rate testing:

(a) Peak-valley ratio (PV): the distance between the highest peak and the deepest valley over the entire evaluation length (Fig. 1).

(b) Root mean square roughness (rms): the standard deviation of the surface roughness measurements relative to mean plane of all the data.

(c) Arithmetic mean roughness $\left(R_{a}\right)$ : the average roughness or deviation of all points from a plane (centre line) fitted to the test surface (Fig. 2).

All tested materials are made from identical materials used in the DePuy artificial knee joint replacement (P.F.C. ${ }^{\circledR}$ Sigma ${ }^{\circledR}$ Revision Knee System).

Tensile testing was conducted by gripping the ends of a standardised test specimen made of UHMWPE in a tensile testing machine (Fig. 3) and then applying a gradually increasing axial load until failure occurred. Several calculations to describe the biomechanical properties of the material were obtained. Stress is the force applied per unit cross-sectional area $\left(\mathrm{N} / \mathrm{m}^{2}\right)$. Strain is the change in length divided by the original length. The stress obtained at the highest applied force is the ultimate tensile strength. The stiffness is the resistance of material to deformation while

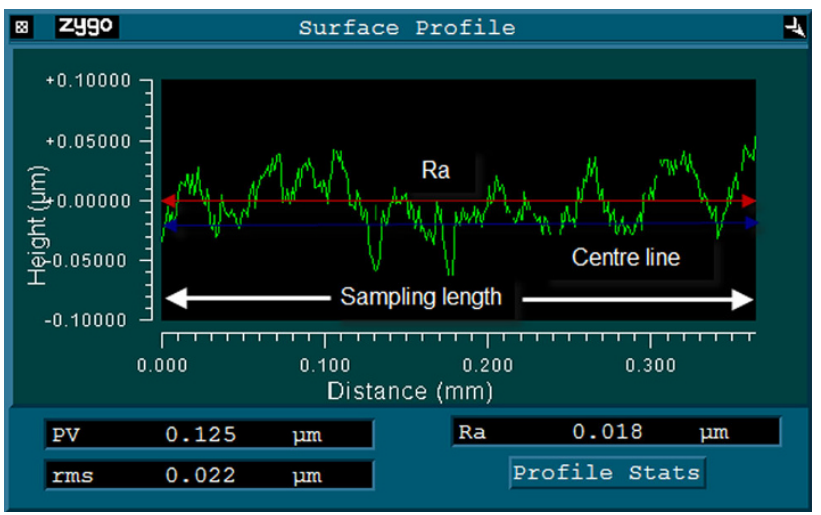

Fig. 2 Surface roughness average $\left(R_{\mathrm{a}}\right)$ : the arithmetic mean roughness of all points from a plane (centre line) fitted to the test surface 
Fig. 3 Tensile testing machine with a mounted specimen made of UHMWPE

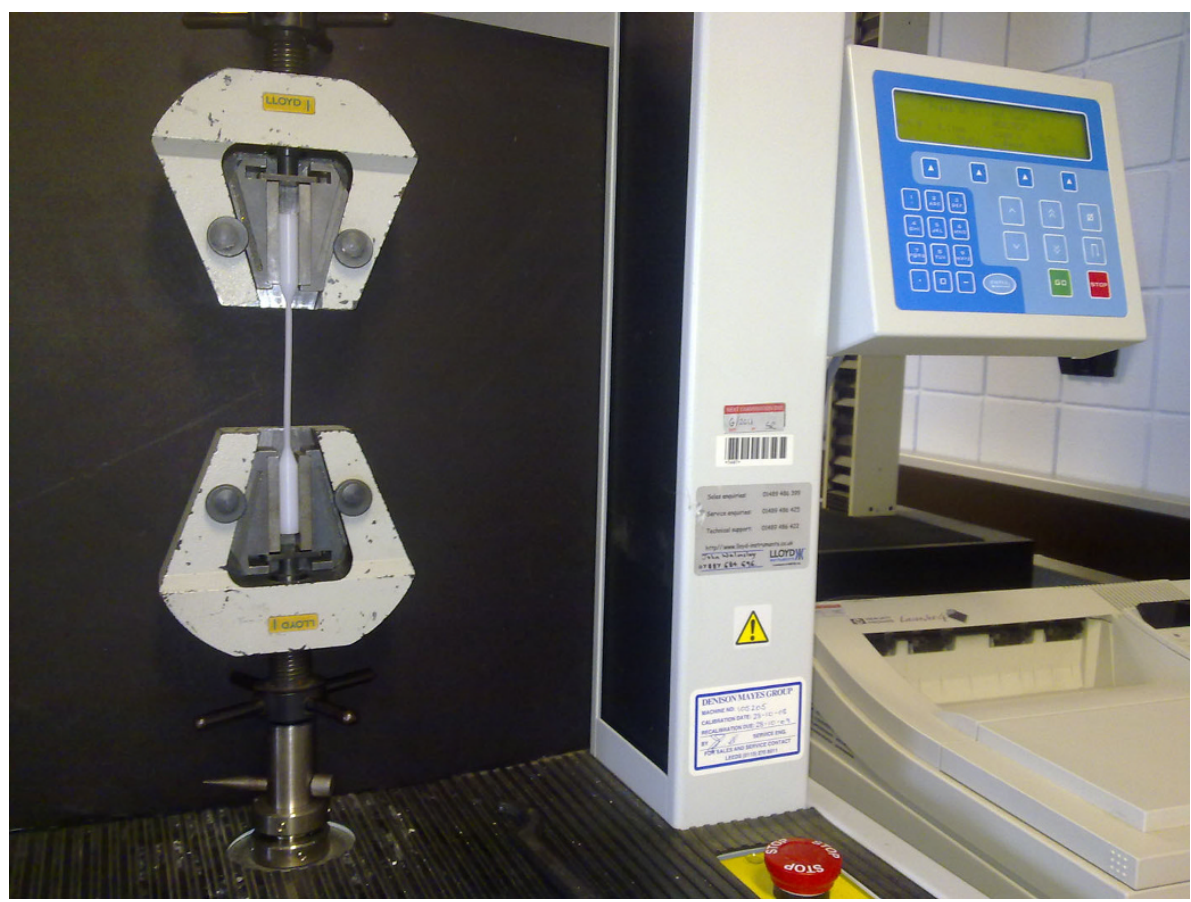

Young's modulus is found by dividing the stress by the strain over the linear portion of stress strain curve [22].

Fifteen dumbbell-shaped tensile specimens were made of UHMWPE-five were soaked in TXA solution (1 g/ $50 \mathrm{ml}$ saline) for $48 \mathrm{~h}$, five were soaked in $50 \mathrm{ml}$ of saline and the other five were used to standardise the tensile testing machine. The duration of soaking of the tested material was based on the pharmacokinetics properties of TXA in the human body. TXA half-life time is $3.5 \mathrm{~h}$ and the human body needs $24 \mathrm{~h}$ to clear $90 \%$ of administered TXA.

Wear rate testing was performed to assess the influence of TXA under accelerated body wear conditions. This test was performed using a multidirectional pin-on-plate machine (Fig. 4). It is a four-station machine applying both reciprocational and rotational motion. The reciprocation was applied by a sledge moving forward and backward over a $4 \mathrm{~cm}$ range at 60 cycles $/ \mathrm{min}$. The heated bed, lubricant tray, level sensor and plate holders were positioned on this sledge.

The plates were made of $\mathrm{Co}-\mathrm{Cr}-\mathrm{Mo}$. Four plates were fitted to the tray and secured with three metal plates and screws. They were covered with lubricant and heated to $37^{\circ} \mathrm{C}$ (body temperature). The pins were made of UHMWPE. Each pin was numbered, notched and tightly fitted to the pin holders at the end of each motor. The rotational frequency was also set at 60 cycles/min $(1 \mathrm{~Hz})$.

The lubricant used in all tests was a $24.5 \%$ concentration of bovine serum (protein content $15 \mathrm{~g} / \mathrm{l}$ ) and was prepared following a standardised protocol.
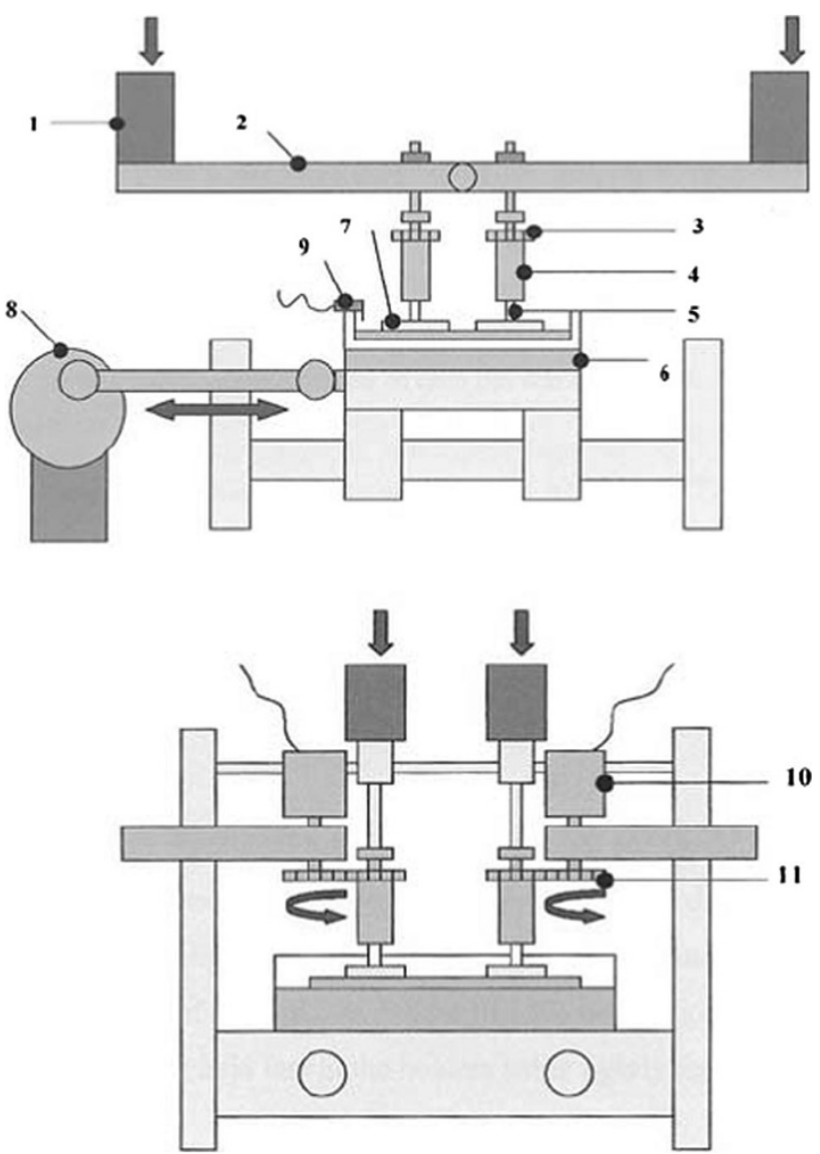

Fig. 4 Schematic diagram of the pin-on-plate machine. 1 weight to provide load, 2 lever arm, 3 gear, 4 pin holder, 5 UHMWPE pin, 6 heater bed, $7 \mathrm{Co}-\mathrm{Cr}-\mathrm{Mo}$ plate, 8 motor to provide reciprocation, 9 level sensor, 10 motor, 11 gear). Reproduced with permission of SAGE Publications Ltd, London, UK 
Fig. 5 Profilemeter view of surface topography of a $\mathrm{Co}-\mathrm{Cr}-$ Mo plate

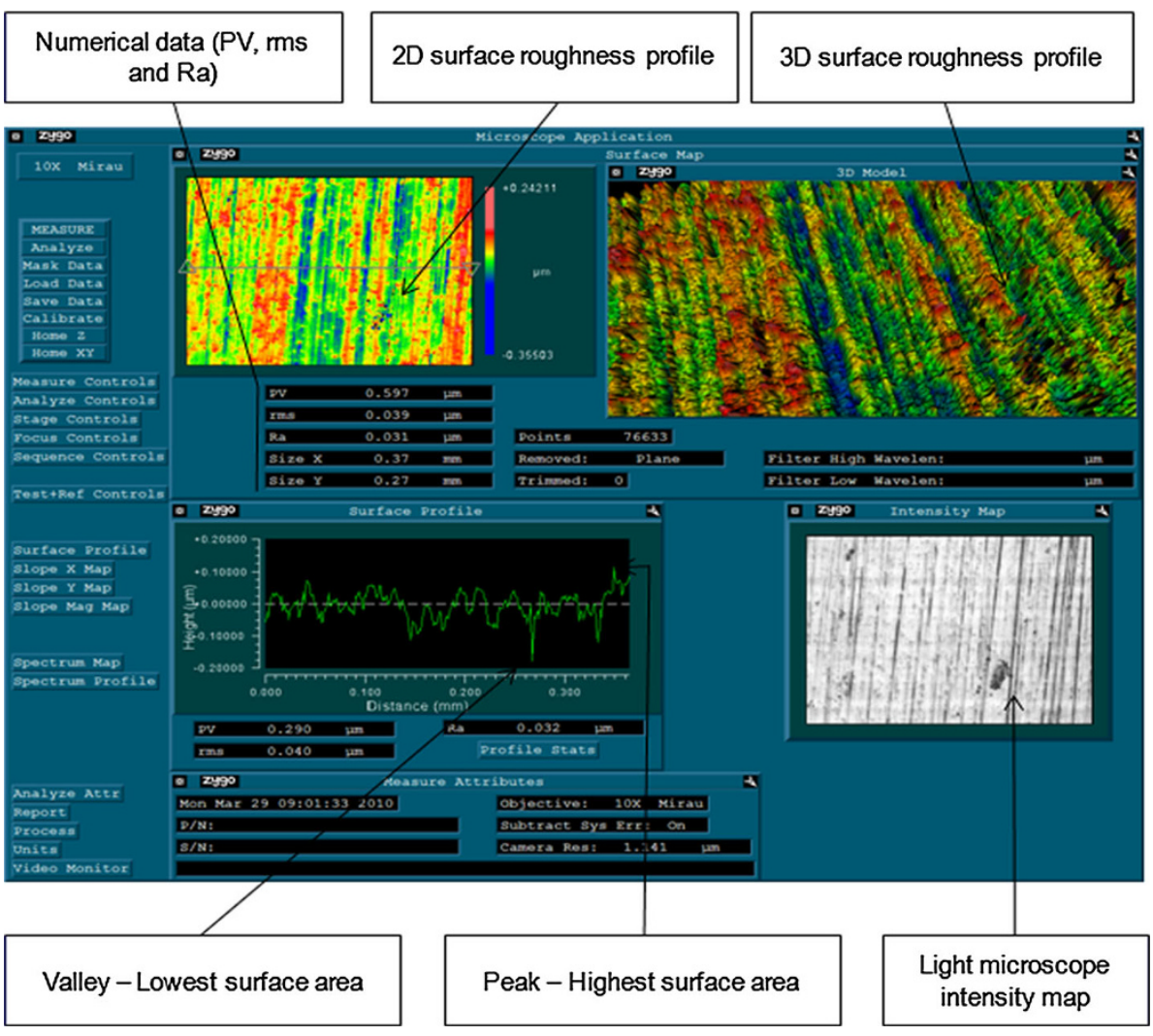

A lubricant level sensor was attached to the lubricant tray to allow the lubricant to be maintained at an almost constant level. Any lubricant loss was assumed to be evaporation of water so this was topped up from a reservoir of distilled water. The rotational motion was provided by four small motors. The four loaded pins were held in stainless steel holders and mounted so that each pin rested on the corresponding plate. A load of $40 \mathrm{~N}$ was applied to each station via a static mass and lever arm mechanism.

The wear was assessed gravimetrically (loss of weight) and volumetric loss was calculated by dividing the mass by the density. Twice a week (approximately every 0.25 million cycles), the machine was stopped to allow for gravimetric assessment and machine maintenance. The pins and plates were cleaned, dried and weighed following a standardised protocol.

Control specimens were used to take account of the absorption of lubricants by both the pins and plates during the test. The wear volumes were plotted against the sliding distance and the gradient of the line provided the wear rate. Wear rate was divided by the load to determine the wear factor, $k\left(\mathrm{~mm}^{3} / \mathrm{Nm}\right)$.

Surface topography measurements were performed using a Zygo NewView 100 non-contacting three-dimensional (3-D) profilemeter. Ten measurements were taken of the pins and plates before and after wear testing. Each measurement provided visual and numerical data of the surface profile of the specimens (Fig. 5). Visual data includes intensity map, 2- and 3-D profiles of surface roughness. This provided a quick scan of a wider area of the specimens to get an overall impression of the roughness of the surfaces. Numerical data included PV, rms and $R_{a}$.

\section{Results}

The tensile test showed that the stiffness, Young's modulus, load to fracture and stress at fracture values were not affected by immersion in TXA or saline for $48 \mathrm{~h}$.

The two groups were comparable in term of stiffness, Young's modulus of elasticity, load at break and stress at break (Table 1). There were no statistically significant differences between saline- and TXA-immersed UHMWPE.

The stiffness, Young's modulus, load to fracture and stress at fracture of the soaked specimens (TXA and saline) were comparable to those of control specimens (nonsoaked specimen) (ANOVA; $P=0.79,0.79,0.67$ and 0.67 , respectively).

The stress strain curves of the ten tensile specimens are shown in Fig. 6. The graph shows all specimens have an almost identical stress strain curve apart from control specimen number five which failed at a lower stress. However, this did not adversely affect the overall findings. 
Table 1 Tensile test results of the UHMWPE specimens

\begin{tabular}{|c|c|c|c|c|c|}
\hline Variable & Specimens & $N$ & Mean (SD) & Mean difference & $P$ value $(95 \% \mathrm{CI})$ \\
\hline \multirow[t]{2}{*}{ Stiffness $(\mathrm{N} / \mathrm{m})$} & Saline & 5 & $81,588(10,518)$ & \multirow[t]{2}{*}{1,964} & \multirow[t]{2}{*}{$0.740(-15,146$ to 11,218$)$} \\
\hline & TXA & 5 & $83,552(7,262)$ & & \\
\hline \multirow[t]{2}{*}{ Young's modulus (MPa) } & Saline & 5 & 923 (119) & \multirow[t]{2}{*}{23} & \multirow[t]{2}{*}{$0.740(-171$ to 127$)$} \\
\hline & TXA & 5 & $946(82)$ & & \\
\hline \multirow[t]{2}{*}{ Load at break $(N)$} & Saline & 5 & $330(33)$ & \multirow[t]{2}{*}{12} & \multirow[t]{2}{*}{$0.523(17$ to -52$)$} \\
\hline & TXA & 5 & $342(20)$ & & \\
\hline \multirow[t]{2}{*}{ Stress at break (MPa) } & Saline & 5 & $47(5)$ & \multirow[t]{2}{*}{1} & \multirow[t]{2}{*}{$0.526(2$ to -7$)$} \\
\hline & TXA & 5 & $48(3)$ & & \\
\hline
\end{tabular}

Fig. 6 Stress strain curves of tensile. Control specimen number 5 which failed at a lower stress is represented with a blue solid line (colour figure online)

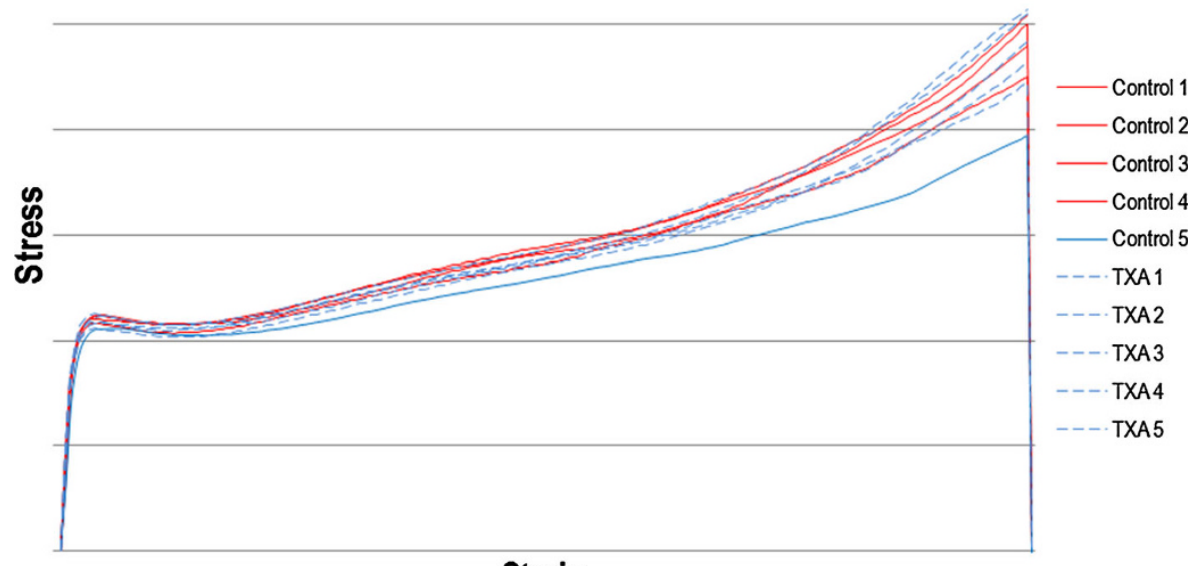

Strain

It is not unusual to have a faulty specimen with a small scratch or defect that affects its tensile properties.

The wear test involved two multidirectional pin-on-plate machines each with four test stations, four control pins and four control plates which were soaked with saline, and four TXA-soaked pins and four-TXA soaked plates. Another two pins and two plates were used as controls to measure the weight changes caused by lubricant absorption. This was deducted from the test specimens at every gravimetric assessment.

Table 2 and Fig. 7 show the cumulative volume changes in the pins and plates in each group (placebo or TXA) as measured each time the machines were stopped. As expected, the main weight loss occurred in the UHMWPE pins rather than the Co-Cr-Mo plates as they are softer and prone to wear more rapidly than plates. Wear factors were calculated for all pins and plates using the following equation:

$\begin{aligned} \text { Wearfactor }= & \text { Volumeloss }\left(\mathrm{mm}^{3}\right) /[\text { slidingdistance }(\mathrm{m}) \\ & \times \operatorname{load}(\mathrm{N})]\end{aligned}$
There were no statistically significant differences between the mean wear factor when comparing either plates or pins which were soaked in saline or TXA as shown in Table 3.

The surface topography testing revealed no significant difference in the $\mathrm{PV}, \mathrm{rms}$ and $R_{a}$ of the plates and pins between the two groups before and after the pin-on-plate wear tests (see Table 4). Hence, the null hypothesis of no difference was supported.

\section{Discussion}

It may take many years to determine the effectiveness of new and innovative designs of artificial joint replacements since many journals refuse to publish new implants series or interventions with $<10$ years followup. Surgeons are cautious about introducing a new intervention without it being carefully studied and assessed. The history of artificial joint replacement supports this caution. 
Table 2 Cumulative volume loss in $\mathrm{mm}^{3}$ in plates and pins

\begin{tabular}{|c|c|c|c|c|c|c|c|c|c|}
\hline \multicolumn{2}{|c|}{ Distance $(\mathrm{km})$} & \multicolumn{4}{|l|}{ Plates } & \multicolumn{4}{|l|}{ Pins } \\
\hline Test 1 & Test 2 & $\begin{array}{l}\text { TXA } \\
\text { test } 1 \text { plate }\end{array}$ & $\begin{array}{l}\text { TXA } \\
\text { test } 2 \text { plate }\end{array}$ & $\begin{array}{l}\text { Placebo } \\
\text { test } 1 \text { plate }\end{array}$ & $\begin{array}{l}\text { Placebo } \\
\text { test } 2 \text { plate }\end{array}$ & $\begin{array}{l}\text { TXA } \\
\text { test } 1 \text { pin }\end{array}$ & $\begin{array}{l}\text { TXA } \\
\text { test } 2 \text { pin }\end{array}$ & $\begin{array}{l}\text { Placebo } \\
\text { test } 1 \text { pin }\end{array}$ & $\begin{array}{l}\text { Placebo } \\
\text { test } 2 \text { pin }\end{array}$ \\
\hline 0 & 0 & 0.00000 & 0.00000 & 0.00000 & 0.00000 & 0.00000 & 0.00000 & 0.00000 & 0.00000 \\
\hline 4 & 14.2 & -0.12659 & 0.02191 & -0.00913 & 0.13309 & -0.14354 & -0.87560 & -0.46651 & -0.71412 \\
\hline 12.4 & 24.2 & -0.19679 & -0.00406 & -0.00162 & 0.11503 & -0.44677 & -1.89833 & -0.93122 & -1.67405 \\
\hline 30.5 & 34.8 & -0.19517 & -0.07608 & -0.00446 & 0.16575 & -1.05862 & -2.73446 & -1.13756 & -2.70755 \\
\hline 38.9 & 47.4 & -0.18441 & -0.07993 & 0.00426 & 0.15276 & -1.84989 & -3.74284 & -1.90192 & -3.99762 \\
\hline 49.6 & 60.7 & -0.18949 & -0.04098 & 0.01603 & 0.14566 & -2.76676 & -5.03112 & -3.31760 & -4.91449 \\
\hline 60.8 & 73.7 & -0.19922 & -0.01440 & 0.00751 & 0.13511 & -3.86485 & -6.43065 & -4.53590 & -6.34094 \\
\hline 73.1 & 88.5 & -0.19598 & -0.01481 & 0.01298 & 0.14262 & -5.21055 & -8.03652 & -5.83495 & -7.95219 \\
\hline 84.6 & 109.5 & -0.22113 & -0.02090 & -0.01116 & 0.09170 & -6.11306 & -9.82719 & -7.16450 & -9.54908 \\
\hline 100.9 & 130.6 & -0.20308 & -0.01075 & -0.00122 & 0.14992 & -7.75661 & -10.77636 & -8.57839 & -10.65973 \\
\hline 121.9 & 162.6 & -0.21119 & 0.05336 & 0.00467 & 0.14161 & -8.64477 & -12.32661 & -9.52037 & -12.13821 \\
\hline 149.2 & & -0.20308 & & 0.00426 & & -10.81583 & & -11.57660 & \\
\hline
\end{tabular}

Fig. 7 Graph of volume losses of the pins and plates plotted against sliding distance

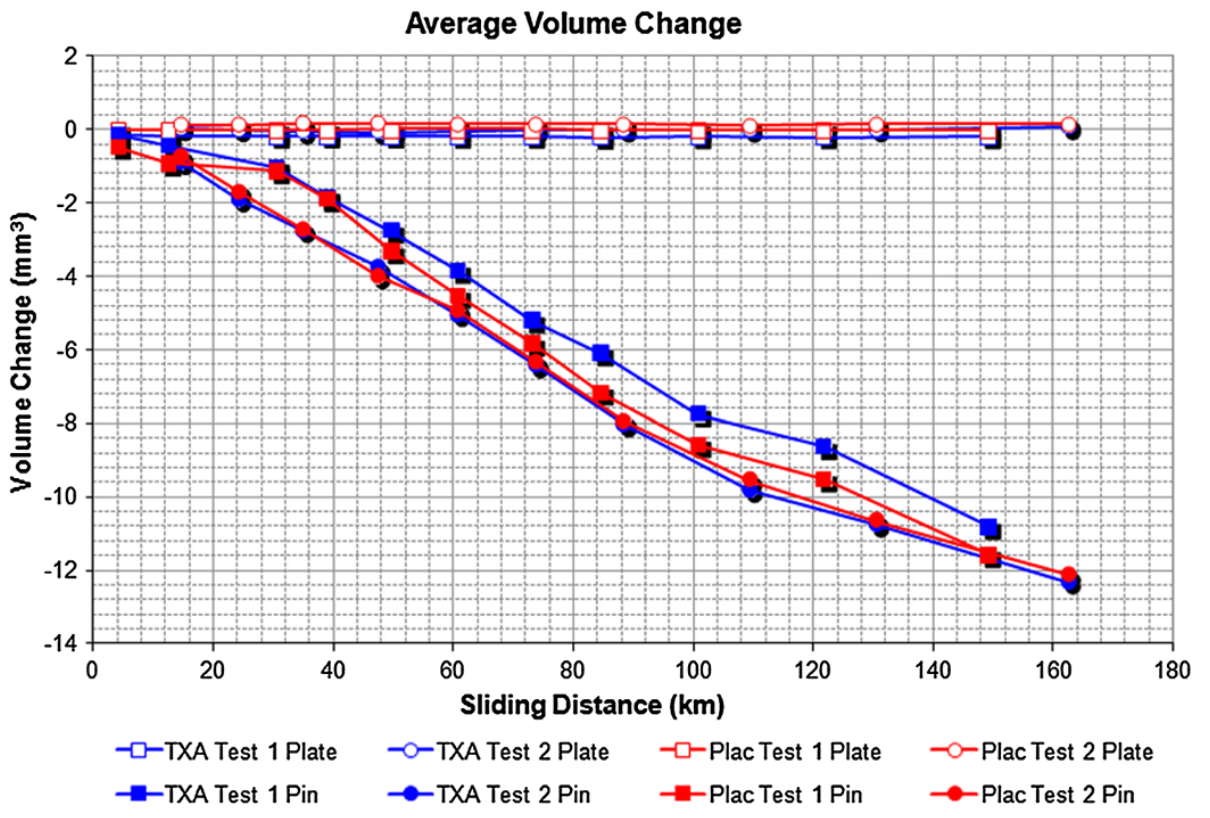

There has been a recent increase in the use of TXA to reduce bleeding and blood transfusion after joint replacement and, more recently, topical application has been advocated without proper safety profile assessment. In this study we investigated the effects of TXA on three important material properties. Tensile testing and surface topography were studied using gold standard methods. This showed there was no difference in the tensile properties and surface topography between the artificial implants that had been soaked in saline and those soaked with TXA.

There are several methods to assess the rate of wear. Clinical and radiological survival analysis of implanted joints is probably the most useful method; however, it takes an extremely long time as some implants can last $>30$ years. Furthermore, patients are often lost to followup during such a long period. Joint simulation is a reliable predictor but it is expensive with limited access. Multidirectional pin-on-plate machines are a reasonable alternative and several studies have confirmed that they are comparable to joint simulators [23-26].

Comparing results from eight stations, there was no significant difference in the wear factor between the two groups and findings were comparable with the wear factors reported in other studies [23, 27]. 
Table 3 The wear factors of plates and pins; parametric $t$ test

Table 4 Post wear surface topography findings

a $\times 10^{-9} \mathrm{~mm}^{3} / \mathrm{Nm}$

\begin{tabular}{lllrlll}
\hline & Groups & $N$ & Mean $^{\mathrm{a}}$ & SD $^{\mathrm{a}}$ & Mean difference $^{\mathrm{a}}$ & $P$ value $(95 \% \mathrm{CI})$ \\
\hline Plates wear factor & Placebo & 4 & 0.00100 & 0.013515 & 0.0035 & 0.768 (-0.161 to 0.023) \\
& TXA & 4 & -0.00250 & 0.008583 & & 0.677 (-0.319 to 0.411) \\
Pins wear factor & Placebo & 4 & 2.15925 & 0.240433 & 0.046 & \\
& TXA & 4 & 2.11325 & 0.177184 & & \\
\hline
\end{tabular}

\begin{tabular}{lllllll}
\hline & Group & $N$ & Mean & SD & Mean difference & $P$ value (95 \% CI) \\
\hline Plates (PV) & Placebo & 3 & 0.279 & 0.228 & -0.0340 & $0.856(-0.5$ to 0.4$)$ \\
& TXA & 4 & 0.313 & 0.240 & & \\
Plates (rms) & Placebo & 3 & 0.021 & 0.0075 & -0.0115 & $0.141(-0.0284$ to 0.0054$)$ \\
& TXA & 4 & 0.0325 & 0.0092 & & \\
Plates $\left(R_{a}\right)$ & Placebo & 3 & 0.019 & 0.002 & -0.007 & $0.187(-0.02$ to 0.005$)$ \\
& TXA & 4 & 0.026 & 0.007 & & $0.195(-5.24$ to 1.32$)$ \\
Pins $(\mathrm{PV})$ & Placebo & 4 & 3.504 & 1.780 & -1.959 & \\
& TXA & 4 & 5.463 & 2.010 & & $0.612(-0.542$ to 0.3531$)$ \\
Pins $(\mathrm{rms})$ & Placebo & 4 & 0.3167 & 0.199 & -0.0715 & \multirow{2}{*}{$0.616(-0.16$ to 0.24$)$} \\
& TXA & 4 & 0.3882 & 0.2216 & & \\
\hline
\end{tabular}

$P V$ Peak-valley ratio $(\mu \mathrm{m}), r m s$ root mean square roughness $(\mu \mathrm{m}), R_{a}$ surface roughness average $(\mu \mathrm{m})$

Authors acknowledge the fact that biomechanical studies do not always correlate well with the clinical outcomes; however, biomechanical tests are widely accepted as the best available predictors and surrogates for future outcomes. Public expectation is that materials used for health reasons need to be tested mechanically or in animal studies before human use. With increasing medical litigation against health care providers, waiting for clinical outcome studies which may take years may not be the option. This study supports the localised usage of TXA around artificial joints used in humans, while accepting the limitations of a laboratory-based study. Separately, members of the team are investigating the 5-year clinical and radiological outcomes of the first 157 patient who underwent total knee replacement using topical TXA in our centre and this will be reported separately.

In summary, laboratory biomechanical testing shows that there are no biomechanical adverse affects on common artificial joint materials exposed to topical TXA. Nonetheless, surgeons using topical TXA are strongly recommended to be vigilant and encouraged to report unexpected premature joint failures associated with topical use of TXA. The National Joint Registry should collect and analyse data on the use of topical TXA, to help inform on-going research into the safety profile of topical TXA in joint replacement.

Acknowledgments The research team would like to thank Dr Roy Harvey and Mr Pete Copley from DePuy International Ltd, Leeds, UK for their support in providing the tested specimens.
Conflict of interest The bioTRANX study was conducted in the Bioengineering Laboratory of the School of Engineering and Computing Sciences, Durham University, Durham, UK between October 2009 and April 2010. All testing materials were provided free of charge by DePuy International Ltd; however, they did not play any role in the investigation.

Open Access This article is distributed under the terms of the Creative Commons Attribution License which permits any use, distribution, and reproduction in any medium, provided the original author(s) and the source are credited.

\section{References}

1. Fischgrund J (2009) Orthopaedic Knowledge Update, 9th edn. The American Academy of Orthopaedic Surgeons, Rosemont, p 840

2. Camarasa MA et al (2006) Efficacy of aminocaproic, tranexamic acids in the control of bleeding during total knee replacement: a randomized clinical trial. Br J Anaesth 96(5):576-582

3. Jansen AJ et al (1999) Use of tranexamic acid for an effective blood conservation strategy after total knee arthroplasty. Br J Anaesth 83(4):596-601

4. Sorin A et al (1999) Reduction of blood loss by tranexamic acid in total knee replacement. J Bone Joint Surg 81-B(Suppl.II):234-234

5. Veien M et al (2002) Tranexamic acid given intraoperatively reduces blood loss after total knee replacement: a randomized, controlled study. Acta Anaesthesiol Scand 46(10):1206-1211

6. Zhang F, Gao Z, Yu J (2007) Clinical comparative studies on effect of tranexamic acid on blood loss associated with total knee arthroplasty. Zhongguo Xiu Fu Chong Jian Wai Ke Za Zhi 21(12):1302-1304 
7. Benoni $\mathrm{G}$ et al (1995) Does tranexamic acid reduce blood loss in knee arthroplasty? Am J Knee Surg 8(3):88-92

8. Benoni G, Fredin H (1996) Fibrinolytic inhibition with tranexamic acid reduces blood loss and blood transfusion after knee arthroplasty: a prospective, randomised, double-blind study of 86 patients. J Bone Joint Surg Br 78(3):434-440

9. Benoni $\mathrm{G}$ et al (2001) Blood conservation with tranexamic acid in total hip arthroplasty: a randomized, double-blind study in 40 primary operations. Acta Orthop Scand 72(5):442-448

10. Benoni G, Lethagen S, Fredin H (1997) The effect of tranexamic acid on local and plasma fibrinolysis during total knee arthroplasty. Thromb Res 85(3):195-206

11. Benoni $G$ et al (2000) Tranexamic acid, given at the end of the operation, does not reduce postoperative blood loss in hip arthroplasty. Acta Orthop Scand 71(3):250-254

12. Molloy DO et al (2007) Comparison of topical fibrin spray and tranexamic acid on blood loss after total knee replacement: a prospective, randomised controlled trial. J Bone Joint Surg $\mathrm{Br}$ 89(3):306-309

13. Orpen NM et al (2006) Tranexamic acid reduces early postoperative blood loss after total knee arthroplasty: a prospective randomised controlled trial of 29 patients. Knee 13(2):106-110

14. Lozano $M$ et al (2008) Effectiveness and safety of tranexamic acid administration during total knee arthroplasty. Vox Sang 95(1):39-44

15. Alshryda $\mathrm{S}$ et al (2011) Tranexamic acid in total knee replacement: a systematic review and meta-analysis. J Bone Joint Surg Br 93(12):1577-1585

16. Sukeik M et al (2011) Systematic review and meta-analysis of the use of tranexamic acid in total hip replacement. J Bone Joint Surg Br 93(1):39-46

17. Wong $\mathbf{J}$ et al (2010) Topical application of tranexamic acid reduces postoperative blood loss in total knee arthroplasty: a randomized, controlled trial. $\mathrm{J}$ Bone Joint Surg Am 92(15):2503-2513
18. Ishida $\mathrm{K}$ et al (2011) Intra-articular injection of tranexamic acid reduces not only blood loss but also knee joint swelling after total knee arthroplasty. Int Orthop 35(11):1639-1645

19. Alshryda $\mathrm{S}$ et al (2013) Topical (intra-articular) tranexamic acid reduces blood loss and transfusion rates following total hip replacement: a randomized controlled trial (TRANX-H). J Bone Joint Surg Am 95(21):1969-1974

20. Alshryda $S$ et al (2013) Topical (intra-articular) tranexamic acid reduces blood loss and transfusion rates following total knee replacement: a randomized controlled trial (TRANX-K). J Bone Joint Surg Am 95(21):1961-1968

21. Panteli $M$ et al (2013) Topical tranexamic acid in total knee replacement: a systematic review and meta-analysis. Knee 20(5):300-309

22. Ramachandran M (2007) Basic orthopaedic sciences. The Stanmore guide. Hodder Arnold, UK, p 304

23. Saikko V (1998) A multidirectional motion pin-on-disk wear test method for prosthetic joint materials. J Biomed Mater Res 41(1):58-64

24. Joyce $\mathrm{TJ}$ et al (2000) A multi-directional wear screening device and preliminary results of UHMWPE articulating against stainless steel. Biomed Mater Eng 10(3-4):241-249

25. Scholes SC, Unsworth A (2007) The wear properties of CFRPEEK-OPTIMA articulating against ceramic assessed on a multidirectional pin-on-plate machine. Proc Inst Mech Eng $\mathrm{H}$ 221(3):281-289

26. Scholes SC, Unsworth A (2001) Pin-on-plate studies on the effect of rotation on the wear of metal-on-metal samples. J Mater Sci Mater Med 12(4):299-303

27. McKellop H et al (1978) Wear characteristics of UHMW polyethylene: a method for accurately measuring extremely low wear rates. J Biomed Mater Res 12(6):895-927 